\title{
Impact of COVID-19 lockdown on surface ozone build-up at an urban site in western India based on photochemical box modelling
}

\author{
Meghna Soni ${ }^{1,2}$, Narendra Ojha ${ }^{1, *}$ and Imran Girach ${ }^{3}$ \\ ${ }^{1}$ Space and Atmospheric Sciences Division, Physical Research Laboratory, Ahmedabad 380 009, India \\ ${ }^{2}$ Indian Institute of Technology, Gandhinagar 382 424, India \\ ${ }^{3}$ Space Physics Laboratory, Vikram Sarabhai Space Centre, Thiruvananthapuram 695022 , India
}

Elevated ozone $\left(\mathrm{O}_{3}\right)$ near the earth's surface causes adverse impacts on human health and vegetation, besides impacting air chemistry and climate. Intense lockdown to contain the spread of Coronavirus disease 2019 (COVID-19) offered a rare opportunity to delineate the anthropogenic impact on urban $\mathrm{O}_{3}$ build-up. In this regard, we incorporated observations of chemical species and environmental conditions into a photochemical box model (NCAR Master Mechanism) to study the $\mathrm{O}_{3}$ changes at a semi-arid urban site in western India (Ahmedabad; $23^{\circ} \mathrm{N}$, $72.6^{\circ} \mathrm{E}$ ). In contrast with primary pollutants, daytime $\mathrm{O}_{3}$ build-up is observed to be enhanced during the lockdown by $\sim 39 \%$. Model, driven by lower nitrogen oxides $\left(\mathrm{NO}_{x}\right)$ during the lockdown, also simulated enhanced $\mathrm{O}_{3}$ (by $\sim 41 \%$ ) showing the role of nonlinear dependence of $\mathrm{O}_{3}$ on $\mathrm{NO}_{x}$. Further, a sensitivity simulation unravelled an important role of the meteorological changes in the $\mathrm{O}_{3}$ enhancement (by $\sim 16 \%$ ) during the lockdown. The results highlight that the lockdown impacts can be modulated profoundly by the complex chemistry plus meteorological changes, offsetting the benefits of lower precursor levels in the context of $\mathrm{O}_{3}$ pollution.

Keywords: Air quality, atmospheric chemistry, COVID-19, trace gases.

\section{Introduction}

IMPACTS of anthropogenic emissions on air pollution are generally understood through model calculations as it is impractical to remove them entirely and observe the reductions. Intense and long lockdowns to stop the spread of the Coronavirus disease 2019 (COVID-19) offered a rare and unique opportunity to study the role of manmade factors in the air quality variations. This is especially the case for short-lived climate forcing pollutants, such as ozone $\left(\mathrm{O}_{3}\right) \cdot \mathrm{O}_{3}$ in the troposphere plays a central role in atmospheric chemistry as the major precursor of the hydroxyl $(\mathrm{OH})$ radical. Besides being an effec-

*For correspondence. (e-mail: ojha@prl.res.in) tive greenhouse gas, when present in elevated concentrations near the earth's surface, $\mathrm{O}_{3}$ has adverse impacts on human health and crop yields ${ }^{1-3}$. In contrast with several primary air pollutants, $\mathrm{O}_{3}$ is not emitted directly and instead gets produced in the atmosphere through chemistry of its precursors carbon monoxide (CO), oxides of nitrogen $\left(\mathrm{NO}_{x}\right)$, and volatile organic compounds (VOCs) emitted from various sources. Photochemical production of $\mathrm{O}_{3}$ depends upon concentrations of precursors in a highly complex and nonlinear manner which also has a strong dependence on solar radiation and other meteorological conditions $^{4,5}$. Considering these complexities, modelling is required to interpret the role of chemistry and meteorological conditions in observed $\mathrm{O}_{3}$ variations.

The tropical Indian region experiences strong and diverse anthropogenic as well as natural emissions. Warmer climate with high water vapour content can favour ozone production, also through biogenic emissions $^{5-9}$. Nevertheless, in situ measurements over this part of the world have been sparse and simulations from chemical transport models have shown significant biases $^{10-12}$. The uncertainties in 3-dimensional models have been associated with input emissions and also with detailed chemistry of hydrocarbons ${ }^{12}$. Zero-dimensional photochemical box models can therefore be a valuable tool as these allow incorporating measured levels of chemical species in prescribed atmospheric conditions $^{11,13,14}$.

To stop the spread of COVID-19, India observed one of the most comprehensive and longest lockdowns of the world. This lockdown resulted in a near zeroing of various anthropogenic emissions except those associated with essential services. Assuming that natural and other factors remain similar, this unprecedented situation offers a rare opportunity to evaluate the air composition in a condition of minimal man-made emissions. Such studies would be valuable in designing emission reduction policies by knowing their potential impacts in given climatic conditions and chemical environments. Considering this, here, we incorporated measurements from ground-based monitoring station and satellite-based instruments into a photochemical box model. The study is conducted for 
Table 1. Different simulations performed in the study with brief descriptions

\begin{tabular}{ll}
\hline Simulation & \\
\hline $\begin{array}{l}\text { Reference simulations } \\
\text { Pre-lockdown }\end{array}$ & Chemical and meteorological inputs set as to pre-lockdown mean conditions \\
Lockdown & Chemical and meteorological inputs set as to lockdown mean conditions \\
Chem_effect & Lockdown simulation but meteorological inputs same as that during pre-lockdown conditions \\
Sensitivity simulations & Similar to simulation - Lockdown, except that VOCs reduced to 40\% of pre-lockdown conditions \\
sens_0.40*voc_lock & Similar to simulation - Lockdown, except that VOCs reduced to 50\% of pre-lockdown conditions \\
sens_0.50*voc_lock & Chemical inputs as in sens_0.40*voc_lock and meteorological inputs same as that during pre-lockdown \\
sens_0.40*voc_chem_eff & Chemical inputs as in sens_0.50*voc_lock and meteorological inputs same as that during pre-lockdown \\
sens_0.50*voc_chem_eff &
\end{tabular}

a semi-arid urban environment in the western India (Ahmedabad; $23^{\circ} \mathrm{N}, 72.6^{\circ} \mathrm{E}$ ). Pre-lockdown and lockdown periods are considered as 1-21 March 2020 and 24 March-10 May 2020 respectively. We performed sensitivity simulation to delineate the effects of reduced levels of precursors versus a change in the meteorology from pre-lockdown to lockdown.

\section{Modelling and input datasets}

The study utilizes the NCAR's Master Mechanism modelversion 2.5 for simulating the surface $\mathrm{O}_{3}$ variations. The model has a highly detailed treatment of gas-phase chemistry by including about 2000 chemical species participating in about 5000 reactions $^{13}$. Time evolution of air parcel initialized with known chemical composition can be simulated by the model in absence of further emissions, dilution or transport effects. Therefore, the model is a tool to probe the effects of changing chemistry in prescribed atmospheric conditions; however, absolute levels of trace gases could differ significantly than measurements since the transport effects are not simulated. Further details and successful applications of this model over the Indian region can be found elsewhere ${ }^{11,14}$.

In this study, three reference simulations have been performed, as summarized in Table 1. Observational values of $\mathrm{CO}$, nitric oxide (NO), nitrogen dioxide $\left(\mathrm{NO}_{2}\right)$ and meteorological conditions (temperature and relative humidity) have been included from the ground-based monitoring station - Maninagar, Ahmedabad available from the Central Pollution Control Board (CPCB). Measurements of $\mathrm{O}_{3}, \mathrm{CO}, \mathrm{NO}_{x}\left(\mathrm{NO}, \mathrm{NO}_{2}\right)$ are based on the absorption of ultraviolet radiation, non-dispersive infrared spectroscopy and chemiluminescence respectively. Observational datasets have been screened prior to the analysis for abnormal values, such as the data points beyond 3-sigma (standard deviation), and recurring values as described in earlier studies analysing these type of datasets ${ }^{7,15}$. Further details on measurement techniques, calibrations and data filtering are available elsewhere ${ }^{16,17}$. As $\mathrm{O}_{3}$ production occurs through the photolysis of $\mathrm{NO}_{2}$, we have constrained the diurnal variations of $\mathrm{NO}_{2}$ in model based on observations (Figure 1) during the lockdown and pre-lockdown. Addi- tionally, model is initialized with typical values of methane and $\mathrm{C}_{2}-\mathrm{C}_{5}$ non-methane hydrocarbons, formaldehyde, etc. based on earlier studies ${ }^{18-21}$ for the pre-lockdown simulation. For lockdown simulation, as discussed earlier also, input $\mathrm{NO}_{x}$ was set (reduced) according to observational data. Following upon a series of sensitivity simulations (Table 1), VOCs were reduced in the model by $45 \%$ compared to the level during pre-lockdown. The key environmental conditions included in the model are summarized in Table 2. Solar irradiance in the simulations is based on the Tropospheric Ultraviolet Visible (TUV) radiative transfer model for Ahmedabad location in prescribed atmospheric conditions. The values of surface albedo and $\mathrm{O}_{3}$ column are based on the Modern-Era Retrospective Analysis for Research and Applicationversion 2 (MERRA-2) model. Aerosol Optical Depth (AOD) and Ångstrom coefficient are from the Moderate Resolution Imaging Spectroradiometer (MODIS) satellite. Model is run for three days and the output for the third day has been used for the analyses.

\section{Results and discussions}

Figure 1 shows the diurnal variations in surface $\mathrm{NO}, \mathrm{NO}_{2}$, $\mathrm{CO}$ and $\mathrm{O}_{3}$ observed at Maninagar station in Ahmedabad during pre-lockdown and lockdown periods. $\mathrm{NO}_{2}$ mixing ratios show double peaks, one during the morning hours (0800-0900 h IST) and other during the evening (2000$2100 \mathrm{~h}$ ); whereas lowest levels are seen during the noontime. In contrast, $\mathrm{O}_{3}$ mixing ratios are observed to be highest during the noontime $(40-60 \mathrm{ppbv})$ and lowest during the night time $(5-10 \mathrm{ppbv})$. Night time $\mathrm{O}_{3}$ observations were not available for most of the days before the lockdown, and therefore here we focus only on daytime $\mathrm{O}_{3}$ build up. Lower $\mathrm{NO}_{2}$ but higher $\mathrm{O}_{3}$ during noontime is manifestation of typical urban chemistry as reported from several stations including Ahmedabad ${ }^{19,22-24}$. Such a strong $\mathrm{O}_{3}$ build-up during noon hours over urban stations is attributed to the photochemistry involving precursors emitted from local-regional sources. $\mathrm{CO}$ and NO mixing ratios show stronger variabilities as reflecting from higher sigma values (standard deviations), nevertheless, the mean values are observed to be lower during the 


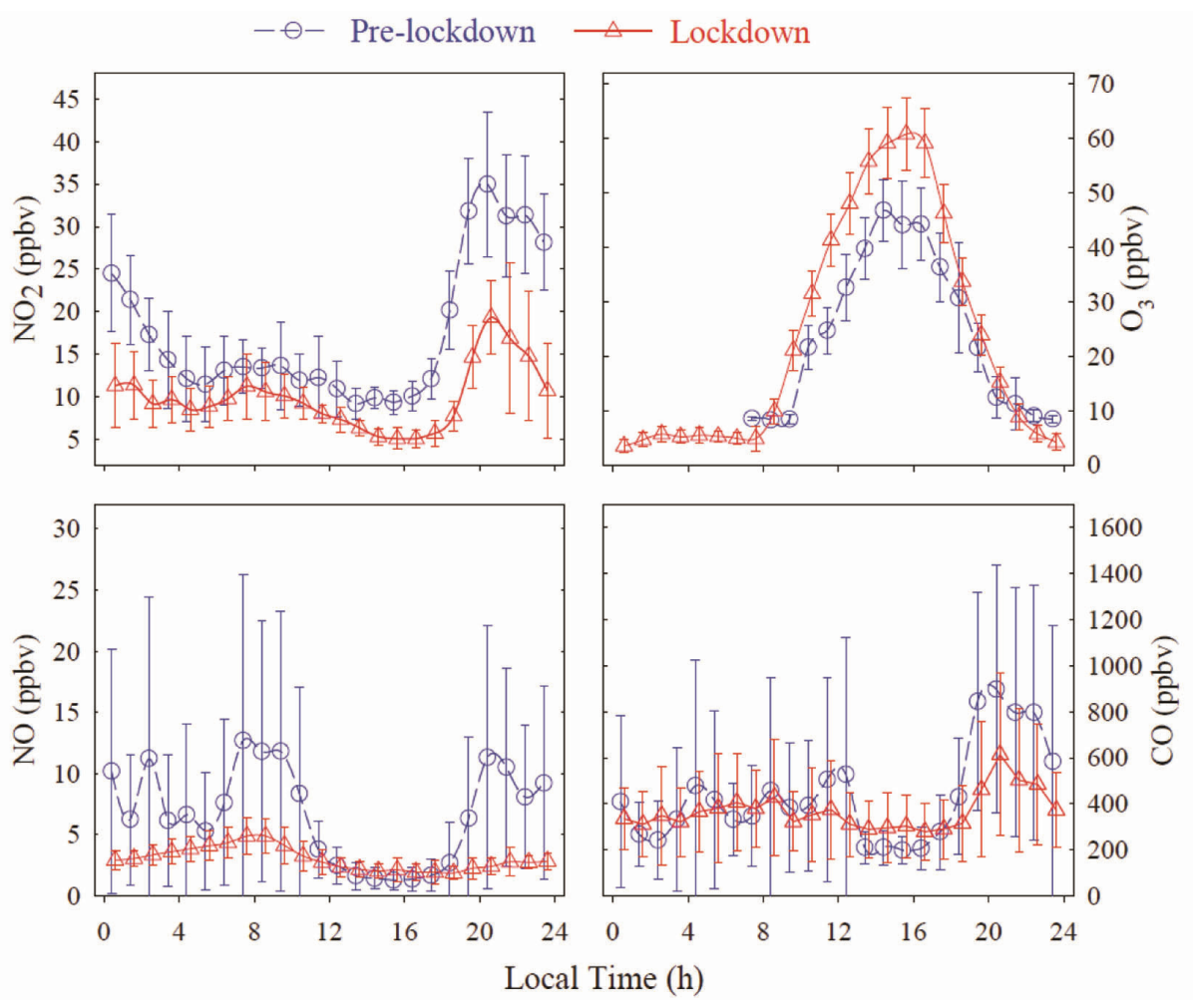

Figure 1. Diurnal variations in surface $\mathrm{NO}_{2}, \mathrm{O}_{3}, \mathrm{NO}$, and $\mathrm{CO}$ observed at Maninagar station in Ahmedabad during prelockdown and lockdown periods. $\mathrm{O}_{3}$ shows stronger daytime build-up during the lockdown, in contrast with $\mathrm{CO}$, $\mathrm{NO}$ and $\mathrm{NO}_{2}$. Error bars show 1-sigma standard deviation.

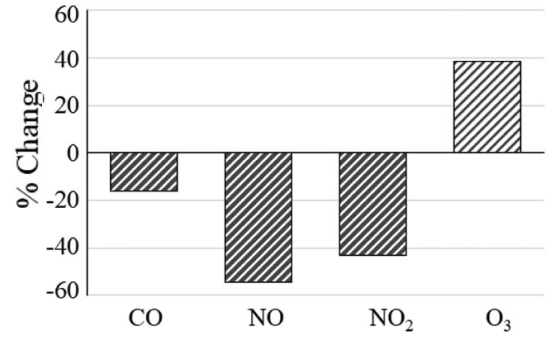

Figure 2. Percentage change in mean values of $\mathrm{CO}, \mathrm{NO}, \mathrm{NO}_{2}$, and daytime (1100-1700 $\mathrm{h}$ IST) $\mathrm{O}_{3}$ during the lockdown compared to the pre-lockdown period.

lockdown. Higher sigma values are suggested to be due to significant day-to-day variations in the local anthropogenic emissions in this urban environment, besides the effects of meteorological variations. Additionally, the morning and evening time peaks in $\mathrm{NO}$ and $\mathrm{NO}_{2}$ are seen to be less pronounced during the lockdown compared to the pre-lockdown condition. Figure 2 shows the percentage change in the mean mixing ratios of $\mathrm{CO}, \mathrm{NO}, \mathrm{NO}_{2}$, and daytime (1100-1700 h IST) $\mathrm{O}_{3}$ during the lockdown compared to the pre-lockdown period. The reductions are observed to be stronger in case of $\mathrm{NO}$ and $\mathrm{NO}_{2}$ (by $\sim 43$ to $55 \%$ ) compared to that in $\mathrm{CO}$ (by $\sim 16 \%$ ). Larger reduction in NO is attributed to the strongly impacted transportation sector in Ahmedabad due to stringent restriction on road traffic during the lockdown. Due to minimal anthro- pogenic emissions during the intense lockdown, the mixing ratios of $\mathrm{O}_{3}$ precursors exhibited sharp decline, as expected. However, daytime $\mathrm{O}_{3}$ mixing ratios showed an enhancement by $39 \%$. We analyse this enhanced $\mathrm{O}_{3}$ build-up in detail based on the photochemical box modelling.

Figure 3 shows a comparison of daytime mean $\mathrm{O}_{3}$ between the pre-lockdown and lockdown conditions from observations and model simulations. As discussed earlier too, the model only simulates chemistry and therefore absolute $\mathrm{O}_{3}$ levels can be different, nevertheless, model does show an enhancement (by $\sim 41 \%$ ) in $\mathrm{O}_{3}$ during the lockdown in agreement with enhancement seen in the observations (by $\sim 39 \%$ ). Higher reduction in NO as compared to $\mathrm{NO}_{2}$ caused enhancement in $\mathrm{NO}_{2} / \mathrm{NO}$ ratio from 2.6 (pre-lockdown) to 3.3 (lockdown), increasing net $\mathrm{O}_{3}$ production. Net enhancement (\%) derived from additional sensitivity simulations is given in Table 3. Since during the lockdown $\mathrm{NO}_{x}$ levels are constrained to lower values based on observations, this result suggests that reductions in VOCs would be required to reduce $\mathrm{O}_{3}$ pollution in this environment. In addition, meteorological conditions have changed from pre-lockdown to lockdown, which could also contribute to the $\mathrm{O}_{3}$ enhancement. Besides other meteorological variables such as temperature and relative humidity (Table 2), solar irradiance is seen to have played most important role. Noontime solar irradiance is 
higher by $58-132 \mathrm{Wm}^{-2}$ during the lockdown compared to the pre-lockdown (Figure 4). Slightly stronger (by 0.5 $1 \mathrm{~ms}^{-1}$ ) and more frequent northerly local winds were observed during the lockdown, as compared to the prelockdown. By incorporating the observed variations in $\mathrm{CO}, \mathrm{NO}$ and $\mathrm{NO}_{2}$, model simulations account for the effects of this change in local dynamics on these species. The relative effects of change in precursor levels and meteorological conditions have been studied further using the model simulations (Figure 5).

Figure 5 shows a comparison of the three reference simulations which are described in Table 1. As discussed

Table 2. Environmental conditions opted for pre-lockdown and lockdown conditions in the model

\begin{tabular}{lll}
\hline Parameter & Pre-lockdown & Lockdown \\
\hline Temperature & $303 \mathrm{~K}$ & $305 \mathrm{~K}$ \\
Relative humidity & $38.5 \%$ & $33 \%$ \\
Total $\mathrm{O}_{3}$ column & $284.1 \mathrm{DU}$ & $283.8 \mathrm{DU}$ \\
Aerosol optical depth at $550 \mathrm{~nm}$ & 0.25 & 0.19 \\
Ångstrom coefficient & 0.75 & 1.141 \\
\hline
\end{tabular}

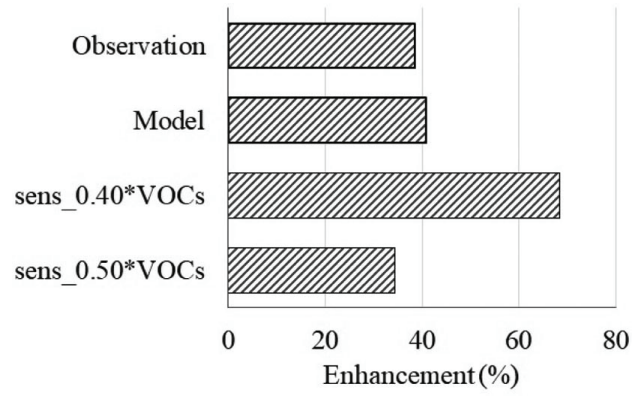

Figure 3. Enhancement in daytime mean (1100-1700 h IST) $\mathrm{O}_{3}$ during the lockdown as compared to pre-lockdown based on observation and model. Results from two additional sensitivity simulations with varying VOCs, as described in the Table 1, are also shown.

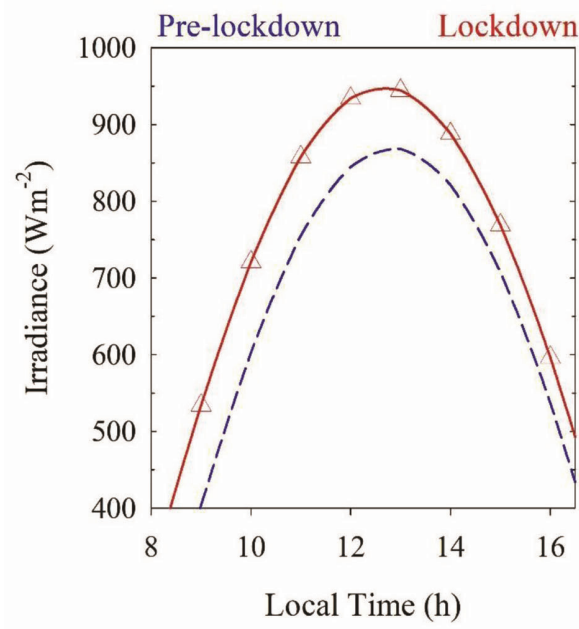

Figure 4. Hourly variation in solar irradiance at Ahmedabad during the pre-lockdown and lockdown condition driving the photochemistry in the model. earlier also, model shows most pronounced $\mathrm{O}_{3}$ build up during the lockdown conditions with a daytime enhancement by $41 \%$, compared to the pre-lockdown simulation. Interestingly, when reduced levels of chemical input are implemented but meteorology (solar radiation, temperature, etc.) is kept the same as that during the pre-lockdown period, $\mathrm{O}_{3}$ enhancement is simulated to be significantly lower (only $25 \%$ as compared to $41 \%$ ). This shows that the enhancement in $\mathrm{O}_{3}$ was caused by both chemistry and meteorological changes. Figure $5 b$ and $c$ shows influence of $40 \%$ and $50 \%$ reductions in VOCs on $\mathrm{O}_{3}$ for lockdown and pre-lockdown conditions. These additional simulations suggest that this interplay of chemistry and meteorology remains important even if levels of VOCs are slightly higher (or lower) than that considered in the reference simulations.

Effect of lockdown on chemistry is further analysed by computing the $\mathrm{O}_{3}$ production and loss rates for the three reference simulations: pre-lockdown, lockdown and chem_effect (Figure 6). $\mathrm{O}_{3}$ production rates are based on the $\mathrm{HO}_{2}+\mathrm{NO}$ and $\mathrm{RO}_{2}+\mathrm{NO}$ reactions, whereas the loss rates are determined using the $\mathrm{O}\left({ }^{1} \mathrm{D}\right)+\mathrm{H}_{2} \mathrm{O}, \mathrm{OH}+\mathrm{O}_{3}$, and $\mathrm{HO}_{2}+\mathrm{O}_{3}$ reactions, as described in the literature $^{10,11,25}$. In all the three cases, $\mathrm{O}_{3}$ production rates increase in the morning to a maximum $\left(8-10.2 \mathrm{ppbv} \mathrm{h}^{-1}\right)$ in the noontime $(\sim 13: 00 \mathrm{~h})$, before starting to decrease. Similarly, the $\mathrm{O}_{3}$ loss rates are also maximum during the noon hours $\left(1.7-3 \mathrm{ppbv} \mathrm{h}^{-1}\right)$. This supports the discussion on observed and modelled $\mathrm{O}_{3}$ diurnal variations that $\mathrm{O}_{3}$ build up in this environment is dominated by the local photochemistry. Here, it is clearly seen that the $\mathrm{O}_{3}$ production rate is higher during the lockdown condition (up to $10.2 \mathrm{ppbv} \mathrm{h}^{-1}$ ) in comparison with the pre-lockdown condition (up to $8 \mathrm{ppbv} \mathrm{h}^{-1}$ ). When meteorological conditions are not changed and only chemical inputs are changed to the lockdown condition (Chem_effect simulation), the $\mathrm{O}_{3}$ production rate is found to $\overline{\mathrm{b} e}$ higher than pre-lockdown (by up to $0.4 \mathrm{ppbv} \mathrm{h}^{-1}$ ). Since, besides production, the loss rates have also been impacted by the chemistry and meteorology, the net production rates (production minus loss) have also been considered to see the overall effect. The net $\mathrm{O}_{3}$ production rate is estimated to be higher during the lockdown than those during the pre-lockdown by up to $1.2 \mathrm{ppbv} \mathrm{h}^{-1}$. The analyses highlight that while the lockdown had a remarkable impact in reducing levels of primary pollutants, any potential benefits in context of $\mathrm{O}_{3}$ air quality can get offset by chemistry and meteorology. Our findings suggest that these effects should be considered while planning to curb $\mathrm{O}_{3}$ pollution in this environment in the future.

\section{Summary and conclusion}

An intense and comprehensive lockdown implemented to minimize the spread of COVID-19 reduced anthropogenic 
Table 3. Contribution of chemistry and meteorology in the enhancement of daytime $\mathrm{O}_{3}(\%)$ during lockdown based on reference and sensitivity simulations

\begin{tabular}{lccc}
\hline Simulation & $\mathrm{O}_{3}$ enhancement (\%) & Contribution of chemistry (\%) & Contribution of meteorology (\%) \\
\hline Lockdown & 41 & 25 & 16 \\
sens_0.40*voc_lock & 68 & 48 & 20 \\
sens_0.50*voc_lock & 34 & 16 & 18 \\
\hline
\end{tabular}
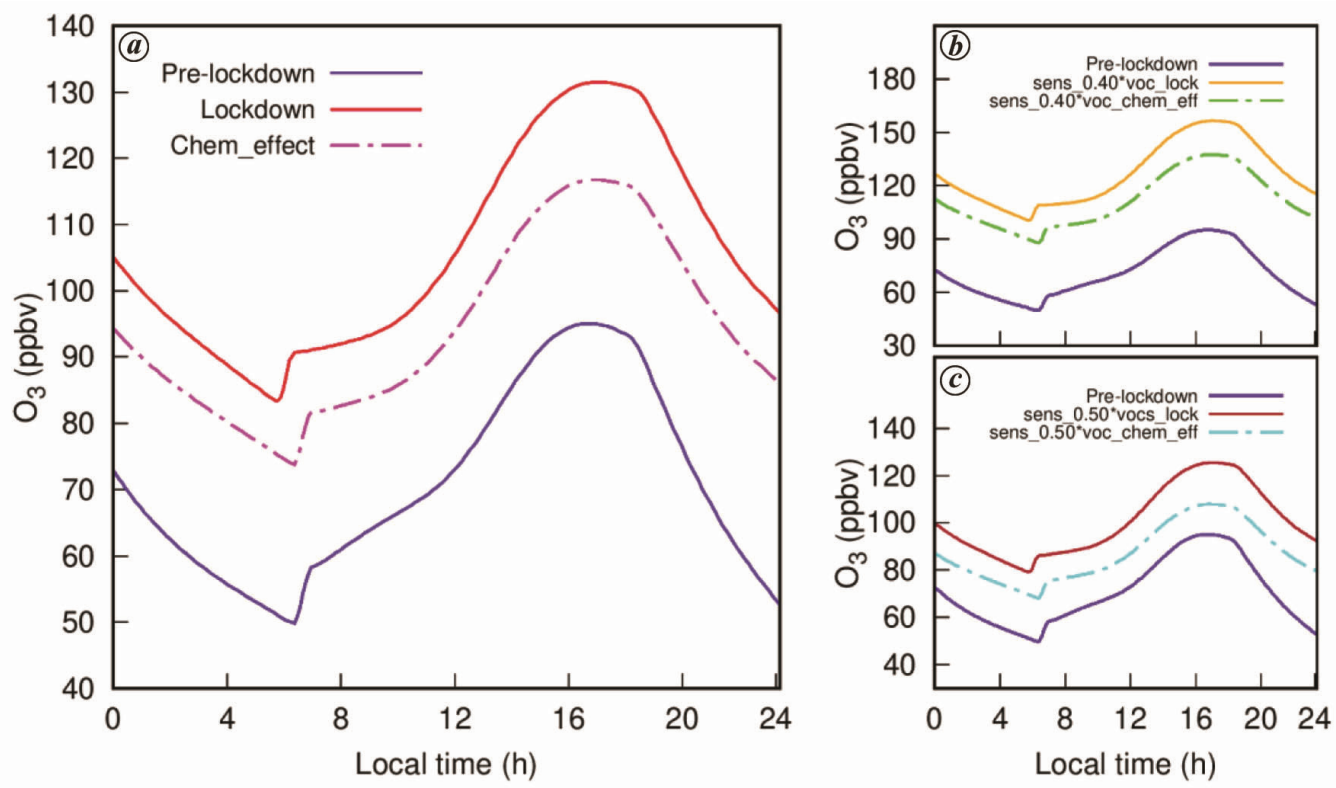

Figure 5. $\boldsymbol{a}$, Comparison of model simulated $\mathrm{O}_{3}$ for pre-lockdown and lockdown conditions. Chem_effect is an additional simulation with chemical inputs of lockdown but meteorological inputs of pre-lockdown. $\bar{b}$ and $\boldsymbol{c}$, Results from two additional simulations with varying VOCs, as described in Table 1, are also shown.

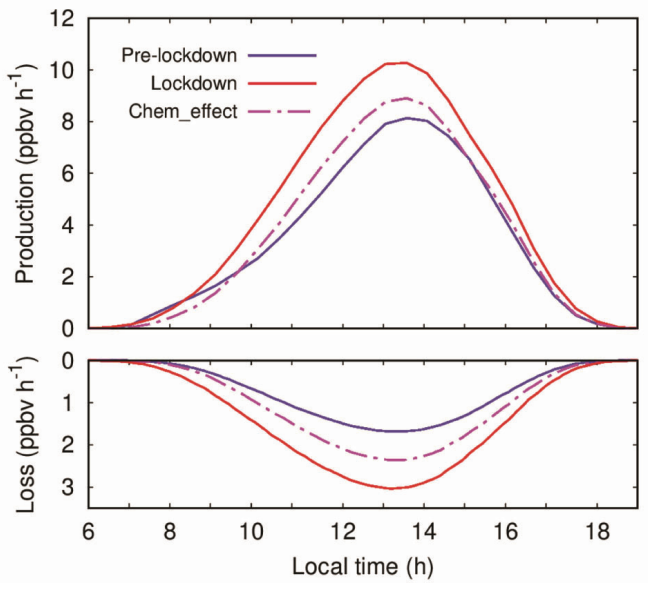

Figure 6. Diurnal variation in $\mathrm{O}_{3}$ production and loss rates for prelockdown and lockdown conditions derived from model simulations. Chem_effect is an additional simulation with chemical inputs of lockdown but meteorology same as that during the pre-lockdown.

emissions across India drastically. Although this led to a remarkable improvement in the air quality in context of primary gases, $\mathrm{O}_{3}$ pollution did not show a reduction instead showed more build up during the lockdown at an urban site in Ahmedabad. Model reproduced this feature of enhancement in daytime $\mathrm{O}_{3}$ production in lower $\mathrm{NO}_{x}$ conditions of lockdown. Meteorological changes, most importantly higher solar irradiance, contributed to more intense photochemistry during the lockdown. Model derived net $\mathrm{O}_{3}$ production rate was higher by up to $1.2 \mathrm{ppbv} \mathrm{h}^{-1}$ during the lockdown than that during the pre-lockdown. Sensitivity simulations were performed to quantify the relative effects of change in precursor levels and meteorological conditions. The analysis revealed that the meteorological changes enhanced $\mathrm{O}_{3}$ by $\sim 16 \%$ whereas additional $25 \%$ enhancement was due to chemistry. The study highlights that the effects of emission reductions could get modulated by complex chemical processes and meteorological variations and therefore intense lockdown might not have yielded anticipated reductions for some pollutants. The findings could prove valuable in planning strategies to curb $\mathrm{O}_{3}$ pollution in future by considering the effects of chemistry and atmospheric conditions in this semi-arid urban environment.

1. Lelieveld, J. et al., The contribution of outdoor air pollution sources to premature mortality on a global scale. Nature, 2015, 525, 367-371; https://doi.org/10.1038/nature15371.

CURRENT SCIENCE, VOL. 120, NO. 2, 25 JANUARY 2021 
2. Ghude, S. D. et al., Premature mortality in India due to $\mathbf{P M}_{2.5}$ and ozone exposure. Geophys. Res. Lett., 2016, 43, 4650-4658; doi:10.1002/2016GL068949.

3. Sharma, A., Ojha, N., Pozzer, A., Beig, G. and Gunthe, S. S., Revisiting the crop yield loss in India attributable to ozone. Atmos. Environ., 2019, X, 1:100008; doi:https://doi.org/10.1016/j.aeaoa. 2019.100008

4. Jacob, D., Introduction to Atmospheric Chemistry, Princeton University Press, New Jersey 1999; doi:10.2307/j.ctt7t8hg.

5. Coates, J., Mar, K., Ojha, N. and Butler, Tim., The influence of temperature on ozone production under varying $\mathrm{NO}_{x}$ conditions a modelling study. Atmos. Chem. Phys., 2016, 16, 11601-11615; 10.5194/acp-16-11601-2016.

6. Akimoto, H., Global air quality and pollution. Science, 2003, 302(5651), 1716-1719; doi:10.1126/science.1092666.

7. Ojha, N. et al., On the widespread enhancement in fine particulate matter across the Indo-Gangetic Plain towards winter. Sci. Rep., 2020, 10, 5862; https://doi.org/10.1038/s41598-020-62710-8.

8. Gunthe, S., Beig, G. and Sahu, L., Study of relationship between daily maxima in ozone and temperature in an urban site in India Curr. Sci., 2016, 110, 1994-1999; 10.18520/cs/v110/110/19941999.

9. Sahu, L., Tripathi, N. and Yadav, R., Contribution of biogenic and photochemical sources to ambient VOCs during winter to summer transition at a semi-arid urban site in India. Environ. Pollut., 2017; doi: 10.1016/j.envpol.2017.06.091.

10. Kumar, R., Naja, M., Pfister, G. G., Barth, M. C., Wiedinmyer, C. and Brasseur, G. P., Simulations over South Asia using the weather research and forecasting model with chemistry (WRF-Chem): chemistry evaluation and initial results. Geosci. Model Dev., 2012, 5, 619-648; https://doi.org/10.5194/gmd-5-619-2012.

11. Ojha, N. et al., Variabilities in ozone at a semi-urban site in the Indo-Gangetic Plain region: Association with the meteorology and regional processes. J. Geophys. Res., 2012, 117, D20301; doi:10.1029/2012JD017716.

12. Sharma, A., Ojha, N., Pozzer, A., Mar, K. A., Beig, G., Lelieveld, J. and Gunthe, S. S., WRF-Chem simulated surface ozone over south Asia during the pre-monsoon: effects of emission inventories and chemical mechanisms. Atmos. Chem. Phys., 2017, 17, 14393-14413; https://doi.org/10.5194/acp-17-14393-2017.

13. Madronich, S., Chemical evolution of gaseous air pollutants down-wind of tropical megacities: Mexico City case study. Atmos. Environ., 2006, 40, 6012-6018; 10.1016/j.atmosenv.2005. 08.047 .

14. Girach, I. A. et al., The changes in near-surface ozone and precursors at two nearby tropical sites during annular solar eclipse of 15 January 2010. J. Geophys. Res., 2012, 117, D01303; http://dx.doi. org/10.1029/2011JD016521.

15. Schnell, J. L. et al., Exploring the relationship between surface $\mathrm{PM}_{2.5}$ and meteorology in Northern India. Atmos. Chem. Phys., 2018, 18, 10157-10175; https://doi.org/10.5194/acp-18-101572018
16. Technical Specifications for Continuous Ambient Air Quality Monitoring (CAAQM) Station (Real Time), 2019; https://cpcb.nic. in/report.php

17. Singh, V., Singh, S., Biswal, A., Kesarkar, A. P., Mor, S. and Ravindra, K., Diurnal and temporal changes in air pollution during COVID-19 strict lockdown over different regions of India. Environ. Pollut., 2020, 266(3), 2020; 115368, ISSN 0269-7491, https://doi.org/10.1016/j.envpol.2020.115368

18. Sahu, L. and Lal, S., Distributions of $\mathrm{c} 2-\mathrm{c} 5 \mathrm{nmhcs}$ and related trace gases at a tropical urban site in India. Atmos. Environ., 2006, 40(5), 880-891; doi:https://doi.org/10.1016/j.atmosenv.2005.10.021

19. Mallik, C., Lal, S. and Sethuraman, V., Trace gases at a semi-arid urban site in western India: variability and inter-correlations. $J$. Atmos. Chem., 2015, 72, 143-164; doi:10.1007/s10874-015-9311-7.

20. Chandra, N., Venkataramani, S., Lal, S., Patra, P., Ramonet, M., Lin, X. and Sharma, S., Observational evidence of high methane emissions over a city in western India. Atmos. Environ., 2019, 202, 41-52; doi:https://doi.org/10.1016/j.atmosenv.2019.01.007.

21. Chutia, L. et al., Distribution of volatile organic compounds over Indian subcontinent during winter: Wrf-chem simulation versus observations. Environ. Pollut., 2019, 252, 256-269; doi:10.1016/j. envpol.2019.05.097.

22. Oltmans, S. J. and Levy, H., Surface ozone measurements from a global network. Atmos. Environ., 1994, 28(1), 9-24; https://doi. org/10.1016/1352-2310(94)90019-1.

23. Lal, S., Naja, M. and Subbaraya, B., Seasonal variations in surface ozone and its precursors over an urban site in India. Atmos. Environ., 2000, 34(17), 2713-2724; doi:https://doi.org/10.1016/ S1352-2310(99)00510-5

24. Ojha, N. et al., Surface ozone in the Doon Valley of the Himalayan foothills during spring. Environ. Sci. Pollut. Res., 2019, 26, 19155-19170; https://doi.org/10.1007/s11356-019-05085-2

25. Duderstadt, K. A. et al., Photochemical production and loss rates of ozone at Sable Island, Nova Scotia during the North Atlantic Regional Experiment (NARE) 1993 summer intensive. J. Geophys. Res., 1998, 103, 13,531-13,555; doi:10.1029/98JD00397.

ACKNOWLEDGEMENTS. We thank Shasha Madronich and co-workers for the freely available NCAR Master Mechanism model through the NCAR ACOM website (https://www2.acom.ucar.edu/ modeling/ncar-master-mechanism). We gratefully acknowledge the Central Pollution Control Board, Ministry of Environment, Forest and Climate Change (MoEFCC) for monitoring of trace gases in Ahmedabad (https://app.cpcbccr.com/ccr/\#/caaqm-dashboard/caaqm-landing). Use of MODIS and MERRA-2 datasets and computing resources at PRL (Vikram) are acknowledged. We are thankful to D. Pallamraju, S. Suresh Babu and Anil Bhardwaj for valuable support during the study. Constructive comments and suggestions from anonymous reviewer and the editor are gratefully acknowledged.

doi: $10.18520 / \mathrm{cs} / \mathrm{v} 120 / \mathrm{i} 2 / 376-381$ 